http://dx.doi.org/10.5007/2175-8085.2017v20n2p71/

\title{
A tensão permanente entre expansão e crise do capitalismo: as revoluções tecnológicas e as bolhas financeiras
}

\author{
The permanent conflict between expansion and crisis of capitalism: \\ Technological Revolutions and financial bubbles. \\ Rubem Polo Costa Mafra \\ rubem.mafra@gmail.com \\ Universidade Federal de Minas Gerais - UFMG \\ Márcia Siqueira Rapini \\ msrapini@cedeplar.ufmg.br \\ Universidade Federal de Minas Gerais - UFMG \\ Tulio Chiarini \\ tulio.chiarini@int.gov.br \\ Instituto Nacional de Tecnologia - INT
}

Resumo: Partindo do conceito de paradigmas tecno-econômico desenvolvido por Freeman e Perez (1988) e pela articulação entre o capital produtivo e financeiro (Perez, 2002) na consolidação de cada Revolução Tecnológica associada, este ensaio articula inovação e bolhas financeiras. Nas quatro primeiras Revoluções Tecnológicas - Era da Mecanização; Era do Vapor e das Ferrovias; Era da Engenharia Pesada, Aço e Eletricidade; e Era do Óleo, Automóvel e Produção em Massa - o capital financeiro foi responsável pela especulação econômica relacionada às inovações e à construção de uma nova infraestrutura industrial. A quinta Revolução Tecnológica - Era da Microeletrônica - traz uma peculiaridade: a financeirização da economia modificou a lógica da relação entre o capital produtivo e o capital financeiro. Em outras palavras, o capital produtivo não se sobrepôs ao capital financeiro, o que pode ser explicado por profundas transformações estruturais no capitalismo.

Palavras-chave: Revolução Tecnológica; Bolhas Financeiras; Crises do Capitalismo

\begin{abstract}
In this essay we theoretically articulate innovation and financial bubbles based on the concept of techno-economic paradigms developed by Freeman and Perez (1988) and on the relation between productive and financial capital during each Technological Revolution (Perez, 2002). In the first four Technological Revolutions - Age of Mechanization; Age of Steam and the Railways; Age of Steel, Electricity and Heavy Engineering; Age of Oil, the Automobile and Mass Production - the financial capital was responsible for the economic speculation related to innovation and to the new industrial infrastructure construction. The Fifth Technological Revolution - the Age of Information and Telecommunications - has a peculiarity: the financialization of the economy has modified the relationship between productive capital and financial capital. In other words, the productive capital did not overlap the financial capital, which can be explained by profound structural transformations in the capitalist system.
\end{abstract}

Keywords: Technological Revolution; Financial Bubbles; Capitalism Crisis

Recebido em: 26-09-2017. Aceito em: 27-11-2017.

Rev. Text. Econ., Florianópolis, v. 20 n. 2, p. 71 - 96, ago/dez. 2017 ISSN 2175-8085 


\section{(c)}

\section{INTRODUÇÃO}

Este ensaio apresenta evidências que demonstram que a conduta e o desempenho das empresas são influenciados por Revoluções Tecnológicas. Essas podem ser definidas como rupturas radicais interligadas capazes de formar uma constelação de tecnologias interdependentes que formam um cluster de clusters (isto é, um sistema de sistemas). Desse modo, uma Revolução Tecnológica tem a capacidade de afetar profundamente o sistema econômico e social, resultando no surgimento de um novo paradigma técnico-econômico (PEREZ, 2009).

Será apresentado neste ensaio que, nas quatro primeiras Revoluções Tecnológicas -Era da Mecanização; Era do Vapor e das Ferrovias; Era da Engenharia Pesada, Aço e Eletricidade; e Era do Óleo, Automóvel e Produção em Massa -, o capital financeiro foi responsável pela especulação econômica relacionada às inovações e à construção de uma nova infraestrutura industrial. O capital produtivo, em cada um desses períodos, assumiu a liderança da construção da infraestrutura industrial a partir da forte especulação e do descolamento do preço dos ativos da economia real, isto é, a partir da geração de uma bolha financeira.

Na quinta Revolução Tecnológica - Era da Microeletrônica - também se observa o estouro de uma bolha financeira - Bolha da Internet - porém este não foi condição suficiente para que a lógica produtiva passasse a dominar a lógica financeira. Isso decorre do fato de que um vasto conjunto de transformações histórico-estruturais resultou em uma economia global de complexidade superior à economia que originou os big bangs anteriores (ALBUQUERQUE, 2016).

Dentre essas transformações, destaca-se a financeirização da economia, a qual permitiu modificar a lógica da relação entre o capital produtivo e o capital financeiro. Em outras palavras, o capital produtivo não se sobrepôs ao capital financeiro - de forma que a sistematização teórica proposta pela economista Carlota Perez não é mais capaz de explicar a dinâmica dos paradigmas e das associações entre os capitais. As forças deixaram de se alternar.

O ensaio está estruturado da maneira que se segue: na seção 1 são apresentados, sinteticamente, os esforços teóricos em explicar a relação entre os paradigmas tecno-econômicos e as bolhas financeiras, sem se preocupar em cobrir todos os trabalhos existentes sobre o tema. Na seção 2 são apresentadas as bolhas financeiras das quatro primeiras Revoluções Tecnológicas. Rev. Text. Econ., Florianópolis, v. 20 n. 2, p. 71 - 96, ago/dez. 2017 ISSN 2175-8085 
http://dx.doi.org/10.5007/2175-8085.2017v20n2p71/

Na seção 3 são apresentadas as características da 'Era da Microeletrônica'. Finda-se o ensaio com algumas considerações finais.

\section{OS PARADIGMAS TECNO-ECONÔMICOS E AS BOLHAS FINANCEIRAS}

Kondratiev (1925), no início do século XX, mostra que o desenvolvimento econômico não é caracterizado por um processo de crescimento contínuo e monótono, sendo composto por movimentos que assumem a forma de ondas ${ }^{1}$. A onda longa é dividida em duas fases, denominadas 'ascendente' e 'descendente' e discriminada em quatro partes: prosperidade, recessão, depressão e recuperação.

Durante a 'Prosperidade', há o desenvolvimento com a expansão da produção real e se dá o aumento da renda. O período seguinte, de 'Recessão', vem com o esgotamento do crescimento, causando uma inversão na tendência de longo prazo, uma vez que a forma utilizada para alcançar novos níveis de renda chegou ao seu limite, passando a haver redução da produção, retração na renda e afins. A 'Depressão' é marcada pela generalização das perdas e pela retração acentuada em todos os aspectos. Por fim, a 'Reconstrução' delimita uma nova inflexão e é caracterizada pela retomada do crescimento e da expansão econômica.

De acordo com Albuquerque (2016), Kondratiev associa cada um dos três ciclos longos com mudanças tecnológicas: a Revolução Industrial no caso do primeiro; aperfeiçoamentos no motor a vapor, invenção da turbina, cimento Portland, entre outras inovações, associadas ao segundo ciclo; e o dínamo, motor a combustão, telégrafo, transmissão de energia elétrica, no caso do terceiro.

Os três primeiros ciclos, na Figura 1 denominados de $1^{\circ}, 2^{\circ}$ e $3^{\circ}$ Kondratiev, foram identificados pelo próprio Kondratiev e os dois ciclos seguintes puderam ser identificados com as mudanças tecnológicas provenientes da petroquímica e automóveis, e da tecnologia da informação, respectivamente. Além disso, Kondratiev mostra que não somente a mudança tecnológica, mas também as guerras, as descobertas de ouro e a entrada de novas regiões

\footnotetext{
A principal contribuição de Kondratieff não é a 'descoberta' do fenômeno das ondas longas como é frequentemente imaginado. De acordo com Grinin et al. (2017), sua principal contribuição está no estudo sistemático do fenômeno e do desenvolvimento de uma teoria das ondas longas. Para Grinin et al. (2017) a periodização das ondas longas, levando em conta as grandes revoluções tecnológicas do processo histórico, se daria em três períodos: Neolítico (Revolução Agrária), Revolução Industrial e Revolução Cibernética.
}

Rev. Text. Econ., Florianópolis, v. 20 n. 2, p. 71 - 96, ago/dez. 2017 ISSN 2175-8085 
http://dx.doi.org/10.5007/2175-8085.2017v20n2p71/

geográficas no vínculo comercial com as economias capitalistas são fenômenos endógenos que condicionam o ritmo de desenvolvimento capitalista (ROSENBERG; FRISCHTAK, 1983).

Figura 1 - Ondas longas de Kondratiev.

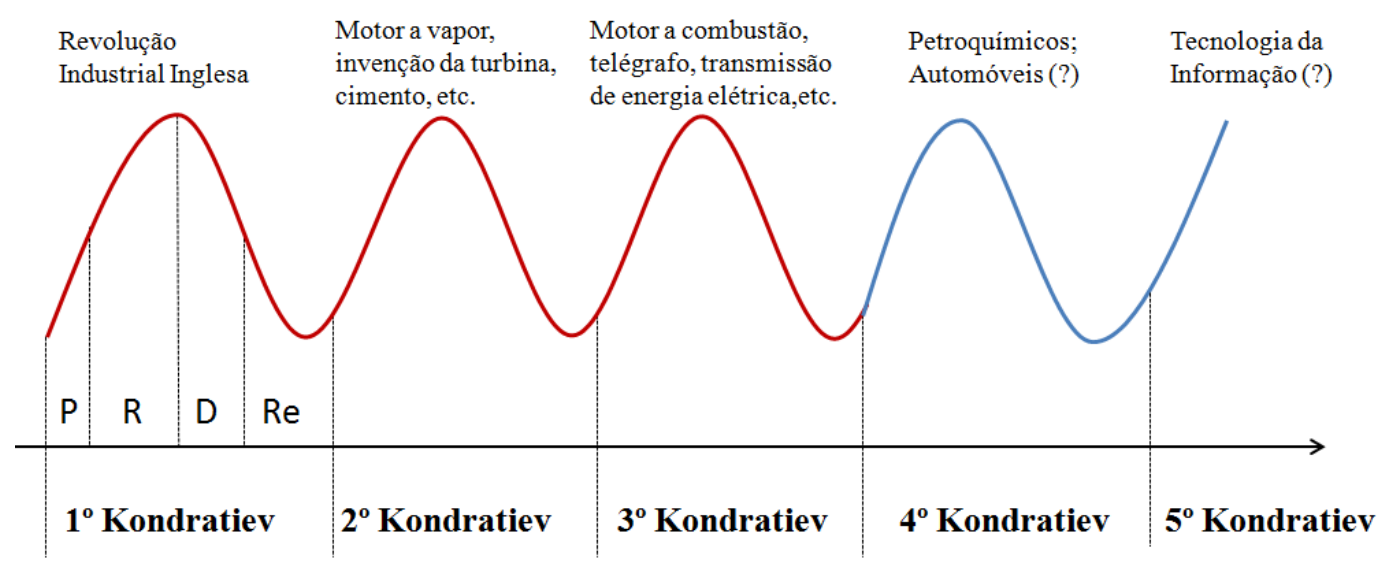

Fonte: Elaboração própria. Nota: $\mathrm{P}=$ Prosperidade; $\mathrm{R}=$ Recessão; $\mathrm{D}=$ Depressão; $\mathrm{Re}=$ Recuperação. Os ciclos em vermelho foram estudados por Kondratiev.

Schumpeter (1939) desenvolve sua teoria das ondas longas no livro Business Cycles. Para Schumpeter (1912) o equilíbrio econômico é rompido através de inovações que, decorrido certo tempo, chega a um novo momentum de equilíbrio. Em sua obra, Schumpeter mostra como essas mudanças ocorrem e como elas iniciam a parte cíclica da economia conseguindo vincular a sua teoria às ondas longas de Kondratiev, dando origem ao chamado ciclo de negócios.

Schumpeter (1943) explica como as inovações possuem uma curva de existência ao longo do tempo, que vão do período inicial de desenvolvimento até o momento completo de conhecimento por parte do mercado. A medida que algumas inovações são mais revolucionárias, Schumpeter (1943) desenvolve o conceito de 'destruição criativa', sendo esse o motor para o crescimento industrial. Em outras palavras, a inovação que surge é responsável por alimentar as indústrias e aumentar a sua eficiência, porém, para que isso aconteça, toda a estrutura existente tem que ser remodelada.

Há algumas mudanças no sistema tecnológico de alcance tão amplo que afetam toda a economia; são os 'vendavais da destruição criadora' (gale of creative destruction) de Schumpeter (1943). Quando um novo paradigma técnico-econômico se torna predominante, transforma-se em um regime tecnológico estabelecido. Tais inovações são de tamanha 'revolução' que podem ser 
http://dx.doi.org/10.5007/2175-8085.2017v20n2p71/

consideradas 'tecnologias de uso geral' ou seja, tecnologias com caráter pervasivo e de natureza sistêmica.

A substituição do 'velho' pelo 'novo' ocorre em surtos (PEREZ, 2002), por isso quando se concretiza a substituição exposta no processo de destruição criativa há uma expansão produtiva de forma eficiente, sendo a justificativa para o período de crescimento da onda (upswing). Da mesma forma, quando surge a necessidade de inovar, há uma clara fadiga da estrutura atual, justificando, assim, a parte de declínio (downswing) da onda e é nesse período em que se concentram estímulos reais à inovação à la Schumpeter (1939).

A inovação possui um tempo de maturação. Quando a inovação gera novas tecnologias, ela pode originar uma Revolução Tecnológica. Perez (2002) vai além das implicações de Schumpeter (1939) e ainda classifica as Revoluções Tecnológicas em mudanças paradigmáticas, isto é, quando são capazes de alterar os diversos setores da economia.

Perez (2002) descreve a cronologia de uma Revolução Tecnológica em quatro fases, articulando o capital produtivo com o capital financeiro. A primeira é a fase de gestação da nova tecnologia, período experimental, com novidades surgindo e gerando um crescimento repentino associado a ela. A segunda é a de expansão da tecnologia em diversos novos produtos e indústrias, o que a autora denomina de constelação completa. A terceira fase representa a exaustão da expansão, ou seja, vai até o seu potencial, atingindo todos os mercados possíveis. Por fim, tem-se a quarta fase, que implica na maturidade de produção, a saturação do mercado consumidor e nos últimos produtos a serem lançados originados pela Revolução Tecnológica em questão.

Essa construção, por Perez (2002), é a forma pela qual ela determina o surgimento de um paradigma tecno-econômico. A origem dele está vinculada aos clusters de inovação onde surgem as primeiras mudanças, caracterizadas na fase um. Portanto, tem-se que uma inovação significativa se torna um paradigma tecno-econômico quando consegue afetar a economia como um todo, gerando transbordamentos que atuam em todos os setores da economia.

Perez (2002) ainda discute a relação entre os paradigmas gerados pelas mudanças tecnológicas e a sua relação temporal, a forma como ocorrem as mudanças de paradigmas ao longo do tempo. A questão temporal é tratada de forma a gerar os surtos de desenvolvimento, através do grau de difusão das tecnologias do novo paradigma oriundas da Revolução Tecnológica. Isso se refere ao fato de o paradigma estar em construção, de haver uma ruptura Rev. Text. Econ., Florianópolis, v. 20 n. 2, p. 71 - 96, ago/dez. 2017 ISSN 2175-8085 
http://dx.doi.org/10.5007/2175-8085.2017v20n2p71/

com as tecnologias vigentes e o surgimento de novas funções na sociedade. O ponto inicial de um surto, é um big bang - explosão da nova tecnologia que vinha sendo gestada. Inicia-se, portanto, a difusão do conhecimento adquirido. Esse surto é superado quando há a substituição do paradigma tecno-econômico, e há outra nova explosão tecnológica. Ao analisar o surto, Perez (2002) o divide em dois momentos principais: o 'período de instalação' e o 'período de desdobramento’ (Figura 2).

Figura 2 - Sequência recorrente na relação entre o capital financeiro e o capital produto em uma onda longa de desenvolvimento.

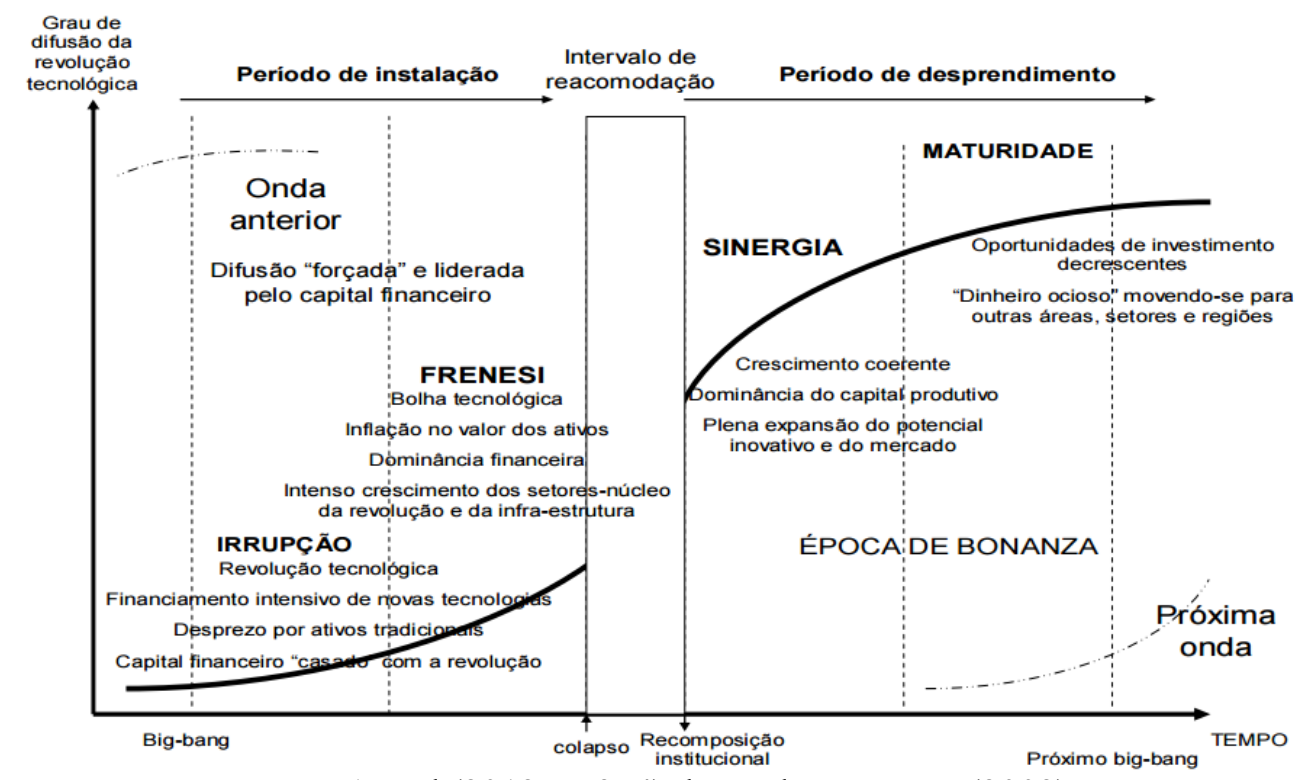

Fonte: Arend (2012, p. 374), baseado em Perez (2002).

O período inicial pode ainda ser subdividido em 'irrupção' e ‘frenesi'. A ‘irrupção’ é o momento em que a Revolução Tecnológica se inicia, ao haver alto grau de desemprego e um declínio da estrutura industrial dominante, há uma forte correlação com a situação econômica o momento de início da difusão do novo paradigma. Já o 'frenesi', representa a expansão acelerada do crescimento vinculado à nova tecnologia. Trata-se do momento de especulação acerca do novo, do descolamento do valor real dos ativos, das novidades que podem surgir com a inovação nascente. $O$ período de instalação é dominado pelo capital financeiro em sua estrutura.

O segundo período, o de desdobramento, pode ser, também, subdividido em duas partes, 'sinergia' e 'maturidade'. $\mathrm{Na}$ 'sinergia' o crescimento econômico é coerente com os investimentos, não há o descolamento nem a especulação, caraterísticas do período anterior. É Rev. Text. Econ., Florianópolis, v. 20 n. 2, p. 71 - 96, ago/dez. 2017 ISSN 2175-8085 
http://dx.doi.org/10.5007/2175-8085.2017v20n2p71/

nesse momento que há um aumento das externalidades do paradigma, da real intervenção na economia e mudança ultrapassa a barreira do imaginário. É nesse período quando ocorrem as chamadas 'eras de ouro' - expansão produtiva e aumento de renda dentro do surto de desenvolvimento analisado.

Como última sub-etapa tem-se a maturidade, momento em que há a saturação do mercado, a consolidação das indústrias, há poucos produtos novos sendo lançados, há certa calmaria em termos de novidade dentro do paradigma tecno-econômico, chegando ao grau máximo de difusão durante a maturidade. Ao contrário do período de instalação, o de desdobramento tem como motor o capital produtivo, daí a sua característica de maior coerência entre produção e crescimento, de valor dos ativos.

O ponto mais interessante na construção dos surtos é o momento de inflexão entre os dois períodos, quando se dá a mudança da dominância da estrutura produtiva do capital financeiro para o capital produtivo. Segundo a proposição de Perez, há um crash que dá início à inversão da estrutura do capital e uma reestruturação institucional que dá o fím à inversão. A principal característica desse ínterim é a formação de uma bolha econômica e o seu estouro no rearranjo produtivo do cenário econômico. O paradigma em questão deixa de ser liderado pelo capital financeiro, especulativo e passa a ser liderado pelo capital produtivo, dando espaço para que o capital financeiro busque inovações para serem estimuladas e impulsionadas, podendo vir a ser a próxima Revolução Tecnológica que gerará outro paradigma tecno-econômico.

Uma análise importante feita por Perez (2002) é a sincronia entre as ondas longas de Kondratiev e os paradigmas tecno-econômicos. Ou seja, a cada uma das ondas longas pode ser atrelada um paradigma e cada uma possui a sua bolha financeira.

Ao longo das fases de instalação da Revolução Tecnológica e do início das mudanças paradigmáticas, a sociedade vive um momento de euforia. A possibilidade do novo atrai especulações e movimenta o setor financeiro. Esse poder assimétrico atribuído aos financistas acaba por ocasionar um abismo entre o que é real e o que realmente é especulativo. Ao se perceber a verdadeira dimensão da revolução, ou que diversos investimentos não proporcionam o resultado esperado, o mundo entra em colapso e os ativos perdem valor em velocidade acelerada. Perez (2002) mostra que esse momento de inflexão é inerente ao sistema, pois é justamente essa alocação de recursos em excesso pelo sistema financeiro em novas tecnologias que causa o 
http://dx.doi.org/10.5007/2175-8085.2017v20n2p71/

descolamento de valores, quando, torna-se insustentável, a economia quebra, e alternam-se as expectativas e as crenças da sociedade.

Quando ocorre a crise, a economia tende a entrar em retração, as pessoas perdem a confiança nos mercados (sobretudo no financeiro) e as empresas, não raras vezes, deixam de pagar as dívidas dos empréstimos tomados. A propagação do pânico pode levar à ruptura do sistema de pagamentos e à corrida bancária (COUTINHO; BELLUZZO, 1998). A economia entra em retração e o novo motor de crescimento passa a ser o capital produtivo. Nesse contexto, buscam-se formas de financiamento internas às organizações, aumentam as restrições para empréstimos e as decisões de investimento são feitas no campo da economia real, na produção efetiva e não mais na geração do dinheiro pelo dinheiro (lógica D-D’ proposta por Marx). Com isso, inicia-se a sinergia, o momento de expansão do capitalismo de forma mais calma e sustentável, onde ocorrem as chamadas eras de ouro.

A novidade da teoria exposta por Perez (2002) está relacionada ao papel desempenhado pelo capital financeiro no desenrolar dos surtos de desenvolvimento, base para o sistema ondulatório de longo prazo no capitalismo. A autora destaca em cada uma das fases como se articulam as instituições financeiras, como se dá a movimentação de capital e, também, quando esse assume a dianteira da atividade econômica.

De acordo com a divisão, na parte inicial, a de instalação, a forma predominante é a do capital financeiro, com forte viés especulativo. A onda anterior possui papel central na formação da onda nova, uma vez que na fase de maturação se forma o idle money (PEREZ, 2002), que é o capital acumulado pelas empresas centrais na constelação industrial da onda anterior, deslocado para outras atividades, que não a central da empresa.

Por se tratar de uma novidade de investimento, algo que a sociedade ainda não conhece e nem aceita como sendo fundamental, a capacidade de ganhos se torna cada vez mais interessante e os investimentos especulativos passam a ter maiores retornos do que os investimentos em capacidade produtiva, justamente pelo elevado risco inerente ao processo inovativo. Em outras palavras, a fase de 'irrupção’ é caracterizada por inverter a lógica dos investimentos. Ao chegar à 'maturidade', e, portanto, ao esgotamento da capacidade tecnológica, os investimentos em ampliação da capacidade produtiva ou inovações naquele paradigma se tornam pouco rentáveis, diminuindo a sua atratividade. As empresas, em função disso, passam a mudar o foco, e ao invés de reinvestirem os lucros na cadeia de valor, passam a procurar novas formas de lucro. Formas Rev. Text. Econ., Florianópolis, v. 20 n. 2, p. 71 - 96, ago/dez. 2017 ISSN 2175-8085 
http://dx.doi.org/10.5007/2175-8085.2017v20n2p71/

essas, que são atraídas justamente pelo despertar do novo paradigma tecno-econômico (PEREZ, 2002).

Ainda na fase de 'instalação', o surto migra para o 'frenesi'. Segundo Perez (2002), é nesse momento que o capital financeiro passa a ter vida própria, se deslocando da realidade. A migração de investimentos começa a ser canalizada para novas tecnologias que se mostram promissoras, iniciando-se assim o processo de criação de infraestrutura da nova tecnologia dominante que só se concretizará depois da era de ouro.

Esse excesso de capital acaba por desvincular da realidade os valores dos ativos financeiros. As expectativas de retorno se tornam exorbitantes e cada vez mais capital é despejado dentro de um conjunto de invenções ainda incipiente, inflacionando de forma descontrolada os papéis. A consequência mais palpável desse descontrole é a instabilidade que toma conta do período e o rompimento da capacidade de pagamento dos elos mais fracos da, agora, antiga economia.

A nova conjuntura proporcionada ao final da instalação exponencializa os ganhos especulativos sobre as novidades tecnológicas, alavancando inúmeros fundos, e, como esperado, descolando os ativos dos valores reais. Forma-se uma bolha econômica. Para Perez (2002), a coevolução da revolução tecnológica e dos mecanismos de financiamento no estabelecimento de um novo paradigma tecno-econômico resultará sempre em uma bolha financeira.

De acordo com Perez (2002), para que aconteça a mudança paradigmática no decorrer da onda longa, é necessário que ela percorra três esferas. A primeira é de que a mudança tecnológica acontece em clusters de inovação radical. Essa esfera representa a revolução tecnológica e o surto de desenvolvimento decorrente dele. A segunda, a separação funcional entre os capitais financeiro e produtivo, e as diferentes formas de ganhos. Por fim, a terceira esfera, a mudança sócio-institucional, onde são compreendidos os reflexos sociais da nova composição econômica e da nova dinâmica da vida em sociedade, uma vez que a inovação radical altera a forma de se viver.

A especulação financeira descontrolada, capaz de movimentar o capital acumulado no paradigma anterior, fomenta o desenvolvimento de novas tecnologias. Porém, quando esse sistema sobrecarrega e colapsa, a sociedade passa a exigir mudanças institucionais capazes de evitar que novamente aconteça o crash, e, dessa forma, evitar-se-ia a depressão que ocorre na passagem do 'frenesi' para a 'sinergia'. É nessa mudança que ocorre a passagem do capital Rev. Text. Econ., Florianópolis, v. 20 n. 2, p. 71 - 96, ago/dez. 2017 ISSN 2175-8085 
financeiro para o capital produtivo como força motriz do crescimento mundial. A consagração das novas tecnologias e a criação de uma rede de infraestruturas concretas, além da construção de uma economia baseada nessa nova estrutura reforça a necessidade de investimento em plantas e atividades econômicas produtivas e não mais em especulações acerca de possíveis novas tecnologias.

Ao contrário do período de instalação, em que há a tendência de concentração de renda, em função da dominância do capital financeiro, a mudança para a sinergia, em função do capital produtivo, passa a expandir a capacidade produtiva e incorpora cada vez mais setores dentro das atividades econômicas. $\mathrm{O}$ financiamento e a oferta de crédito passam a fundamentar a expansão das empresas do core paradigmático, que ainda crescem, fomentam a construção de uma nova rede de infraestrutura, propiciando a modernização das demais atividades econômicas e também o surgimento de novas atividades baseados no novo senso comum (PEREZ, 2002).

À medida que o desenvolvimento tecnológico avança, as tecnologias atingem o final do ciclo, as inovações passam a ser cada vez menos recorrentes e os primeiros sinais de que a maturidade atinge as instituições também aparecem. Assim, o ciclo reinicia-se com a acumulação de capital por parte das empresas que passam a não reinvestir os lucros em capital produtivo, mas em ativos financeiros, movimentando e dispersando os investimentos até totalmente divergi-los da atividade produtiva, fazendo com que o idle money novamente surja e exerça o seu papel de investimento. Ao chegar na última etapa, a maturidade, observa-se a inversão novamente da força motriz, porém, no sentido inverso, do capital produtivo para o capital financeiro. Com a exaustão das capacidades produtivas, dos spillovers tecnológicos, tem-se um direcionamento do capital para novas ideias promissoras. Essa transição, ao contrário do que acontece durante a bolha financeira, ocorre de forma natural e gradativa, com o direcionamento dos lucros recorrentes.

O sistema financeiro é, portanto, o responsável por boa parte do fluxo de evolução da revolução tecnológica, da sua transformação em paradigma tecno-econômico e da mudança para o sistema produtivo. O motivo pelo qual ele é capaz de realizar todas essas funções decorre da sua adaptabilidade às novas realidades. A flexibilidade inerente a essa estrutura institucional faz com que a cada nova realidade, novas tendências se antecipem e sejam as responsáveis pela manutenção da função de oxigenação do sistema produtivo, estimulando novos surtos de desenvolvimento. 
http://dx.doi.org/10.5007/2175-8085.2017v20n2p71/

\section{AS BOLHAS FINANCEIRAS EM CADA PARADIGMA}

A Era da Mecanização

O fator deflagrador do paradigma é a abertura do moinho de Arkwright em 1771. Ele deu início ao período de instalação com diversas novas invenções sendo feitas e analisadas pela sociedade, com algumas sendo rejeitadas e outras incorporadas, como o descaroçador de algodão (1794). Outra invenção que auxiliou o desenvolvimento industrial foi a melhoria do motor a vapor de Watt em 1760. O papel que essas inovações desempenharam foi no desenvolvimento de uma nova realidade industrial na Inglaterra, com o avanço de tecnologias capazes de mecanizar a produção, algo transformador da realidade artesanal, o aperfeiçoamento do ferro forjado e a introdução das primeiras máquinas na linha produtiva. Essas inovações foram peças-chave para a construção da constelação industrial do primeiro paradigma da Revolução Industrial. (PEREZ, 2002).

A evolução da primeira onda longa exigiu uma nova rede de infraestruturas para o seu desenvolvimento. Ao passar para o período de deployment e entrar na era de ouro do paradigma, viu-se inúmeros transbordamentos estruturais, como a construções de canais, turnpike roads e o aperfeiçoamento das rodas d'água. A capacidade produtiva do período não ficou restrita à indústria de algodão, como algumas das inovações iniciais, mas conseguiu se propagar para todas as frentes da economia, auxiliando na alavancagem produtiva de inúmeros setores e modificando a interação da sociedade com a nova realidade. O sistema capitalista evolui com dois subsistemas, um tecnológico-científico e outro sócio-institucional. O desenvolvimento de um novo paradigma na Revolução Industrial alterou as relações sociais e o senso comum das formas produtivas ao introduzir a mecanização e produções fabris em contraponto às formas artesanais e arcaicas do campo e a redução do tempo de transporte por vias fluviais. (PEREZ, 2002).

O aumento da produção e o consequente aumento das exportações fizeram predominar um ambiente de livre comércio e de desregulamentação por parte do governo. Por ter acontecido na Grã-Bretanha, a mudança do modus operandi da sociedade refletiu em decisões do parlamento britânico, tais como a revogação da Lei dos Aprendizes, a confecção da nova Lei dos Pobres e a suspensão dos Combination Acts (LLOYD-JONES, 1990). Não houve só mudanças na legislação, mas também houve levantes contra o novo método de produção em diversos anos do 
período de sinergia como os levantes de 1800, 1808, 1811 e 1816-17 pelos produtores de algodão (LLOYD-JONES, 1990).

Na primeira onda de Kondratiev, a formação da bolha financeira estrutural se deu com o excesso de investimentos relacionados às construções de canais no Reino Unido, como o Bridgewater. Com o início da construção de canais na Europa, como o Canal du Midi, na França, por volta dos anos 1700, que ligava o Mediterrâneo ao Atlântico, os investimentos neste setor começaram a inchar. (PEREZ, 2002).

O sucesso desses canais fez com que inúmeros investidores acreditassem que o investimento valia a pena, porque os casos de sucesso só vinham aumentando ao mesmo tempo em que a produção e a necessidade de escoamento aumentava, porém, a chamada Canal Mania teve a sua duração na última década do século XVIII. Essa Mania pode ser considerada uma 'bolha', pois os valores aportados cresceram de forma vertiginosa, descolando dos valores reais. (PEREZ, 2002).

Houve também o denominado pânico de 1797, quando diversas medidas bancárias restringiram o crédito na Grã-Bretanha, como o Bank Restriction Act de 1797. As consequências dessas medidas foram maiores nos Estados Unidos, onde a restrição de crédito revelou uma rede de comércio no Atlântico completamente dependente dessa oferta creditícia (CHEW, 2005).

O final da década de 1790 mostrou como o capital financeiro tem papel importante na formação econômica de longo prazo e não só nas de curto prazo como é de se esperar. Portanto, o período de turbulência da primeira onda longa de crescimento do capitalismo demonstrou indícios das bolhas financeiras e o papel central da atividade financeira.

De acordo com Perez (2002), foi justamente a formação excessiva dessa infraestrutura produtiva, para conectar as inúmeras cidades antes interligadas apenas via terra, que propiciou com que no período seguinte, na sinergia, houvesse uma efetiva expansão industrial inglesa, com um mecanismo de exportação bastante avançado e com alta capilaridade.

\section{Era do Vapor e das Ferrovias}

Com o esgotamento da expansão industrial, novas invenções se fizeram necessárias, principalmente na busca por fontes de energias mais baratas e novas formas de locomoção se mostraram urgentes. Essas necessidades decorrentes do paradigma anterior suscitaram mudanças, Rev. Text. Econ., Florianópolis, v. 20 n. 2, p. 71 - 96, ago/dez. 2017 ISSN 2175-8085 
culminando no teste do Rocket Steam Engine no Reino Unido, em 1829, sendo esse o Big Bang da onda longa que se iniciava (PEREZ, 2002).

O motor a vapor não foi algo novo no período, mas as constantes descobertas científicas e tecnológicas desde 1642 exemplificam a dificuldade de se determinar o início e o fim de um paradigma tecnológico. Porém, consegue-se determinar quando a tecnologia se torna paradigmática em função do seu papel central na construção das constelações de indústrias do novo período e também da capacidade de deslocamento de investimentos financeiros para a tecnologia disruptiva em questão.

As sucessivas melhorias no motor a vapor levaram ao aumento de sua eficiência e de sua popularização como fonte energética, substituindo produtos que antes utilizavam água, tração animal ou tração humana. Outra 'herança' da primeira onda de Kondratiev foi o aumento da produção de ferro, que ganhou um novo uso nas ferrovias, indústria central ao redor da qual gravitam outras indústrias: de motor a vapor, de maquinário de ferro movido a carvão, ferroviária. Os avanços tecnológicos do período renovaram as indústrias têxteis (PEREZ, 2002).

Com a chegada da era de ouro da segunda onda de Kondratiev, a expansão ferroviária alcançou novas invenções, tais como o telégrafo e o serviço postal integrado. Também auxiliou no escoamento das produções de manufaturas, cujo principal spillover foi a ascensão de portos e depósitos, além da intensificação do comércio internacional.

O início do ciclo se dá no esgotamento tecnológico do paradigma anterior, que além de estimular o surgimento de novas tecnologias, como o motor a vapor, a ferrovia ou o telégrafo, foi capaz de possibilitar o acúmulo de capital necessário para realizar novos investimentos com retornos elevados. Por isso, outra característica do período de mudança da força motriz é a capacidade de mobilização de capital, invertendo os investimentos em capital produtivo para o capital financeiro, e, a partir daí, estimulando especulações acerca do novo (PEREZ, 2002).

Houve, com os excessivos investimentos no período, um avanço tecnológico e a elaboração de um novo senso comum, de que as ferrovias passaram a ser o novo status quo dos meios de transporte, além de possibilitar o catch-up de algumas economias, com destaque para a alemã e a americana, no período da sinergia. Porém, os investimentos excessivos causaram pânico no mercado, com a Railway Mania (FREEMAN; LOUÇA, 2002; PEREZ, 2002).

$\mathrm{Na}$ segunda onda de Kondratiev a construção da bolha financeira se deu de forma bastante similar à primeira. A novidade econômica do período, a qual favoreceu uma mudança no Rev. Text. Econ., Florianópolis, v. 20 n. 2, p. 71 - 96, ago/dez. 2017 ISSN 2175-8085 
http://dx.doi.org/10.5007/2175-8085.2017v20n2p71/

comportamento social, foi a construção das ferrovias. O motor a vapor possibilitou o deslocamento de passageiros e cargas para novos lugares em menos tempo, expandindo o alcance e 'encurtando' as distâncias. Alteraram-se, portanto, as relações interpessoais sociais e profissionais.

Outra característica marcante do período foi as tensões sociais causadas pela revolução tecnológica e pela bolha financeira estrutural. A Europa, em 1848, sofreu inúmeras revoltas de cunho político que exigiram uma reconstituição da forma como estava estruturada a economia. De acordo com McKeever e Rapport (2013), as transformações tecnológicas foram as grandes responsáveis pela criação de condições mais favoráveis à ocorrência de revoltas e revoluções populares, visto que o advento do motor a vapor, das ferrovias, do navio a vapor e do telégrafo tiveram papel central na difusão das ideias. Portanto, o desenrolar do paradigma tecnológico teve papel central na difusão das novidades ao redor da Europa, sendo capaz de estimular a onda revolucionária que se viu em 1848.

Os efeitos do capital financeiro, portanto, ultrapassam a esfera econômica e atingem a esfera social. Elas impulsionaram novas transformações e inovações na estrutura institucional capazes de se adequarem à nova realidade.

Era da Engenharia Pesada, Aço e Eletricidade

O surto de desenvolvimento causado pela ascensão das ferrovias chegou ao seu esgotamento, acumulando capital e deslocando-o para novas atividades promissoras. Dessa vez, o foco veio em parceria com o desenvolvimento da ciência (FREEMAN; LOUÇÃ, 2002), com a descoberta da eletricidade e o avanço dos estudos de engenharia pesada. Para Perez (2002), o momento que caracteriza a passagem do período de maturidade do paradigma anterior para a fase de irrupção do paradigma dominante na terceira onda longa de Kondratiev foi a abertura da planta de aço em Pittsburgh (EUA). Assim como nas duas ondas, esse evento marca a mudança em busca de uma nova forma de fomento ao crescimento econômico.

O terceiro surto, iniciado aproximadamente em 1875, foi caracterizado por uma intensa pesquisa científica com as descobertas de Faraday sobre o eletromagnetismo no início do século, mas que conseguiu a devida atenção no decorrer do século XVIII. A sua capacidade de se tornar 
algo comerciável estimulou investimentos, principalmente, na Alemanha e nos EUA na tentativa de desbancarem o Reino Unido como economia dominante (FREEMAN; LOUÇÃ, 2002).

As sucessivas evoluções e a consequente instalação da capacidade produtiva com a eletricidade e a extensiva utilização do aço produziram a era de ouro. Essa foi a época de maior crescimento do capitalismo, não só pelos resultados econômicos, mas pelos impactos na sociedade europeia do período.

Ao longo dos investimentos em novas estruturas econômicas, houve tensões no sistema financeiro mundial. As consequentes tentativas de expansão econômica levaram a inúmeros empréstimos aos países latino-americanos e o financiamento das guerras pela independência levaram a algumas crises internacionais e, portanto, restrições de crédito no cenário internacional. O grande destaque é o caso da Argentina, em 1890, e a própria crise americana de 1893 (PEREZ, 2002). Essas crises também representam o momento em que a atividade financeira em torno da possibilidade de desenvolvimento da nova indústria estava em seu auge de descolamento dos preços dos ativos de seus valores reais.

A terceira onda de Kondratiev mostrou como o sistema financeiro internacional já apresentava indícios de integração e também da sua volatilidade. A crise de 1890, na Argentina, demonstrou que o fluxo financeiro estava atrás de economias capazes de realizar o catch-up tecnológico, e, portanto, houve um fluxo constante de idle money para essas regiões. Porém, com problemas na safra de trigo, o principal produto de exportação argentina (ADELMANN, 2011), os investimentos do período do frenesi buscaram fontes seguras, como o ouro, e não mais os retornos crescentes das novas tecnologias. A busca por ouro e as mudanças econômicas na base monetária americana acabaram por causar corridas nas bolsas de valores por ativos de empresas. Diversas empresas não foram capazes de pagar as dívidas acumuladas em referência aos novos projetos (ADELMANN, 2011).

Nessa onda, a mudança para o capital produtivo se deu de uma forma mais forçada, uma vez que, com a inflação de preços na economia e a corrida internacional pelo ouro, mais de 500 bancos e 15 mil empresas foram fechados, causando uma mudança comportamental no perfil dos investidores. $\mathrm{O}$ foco se tornava a expansão das novas capacidades produtivas determinadas no período de instalação, como a eletricidade e a utilização disseminada do aço (PEREZ, 2002). 


\section{Era do Óleo, Automóvel e Produção em Massa}

A última onda que o próprio Kondratiev (1935) mapeou, foi a quarta. Esta onda, segundo Freeman e Louçã (2002), difere das anteriores, pois se caracterizou por mudanças intangíveis como o desenvolvimento das corporações e novas formas de estrutura de gestão.

A virada do século trouxe mudanças para a sociedade: novas tecnologias como os veículos automotores (automóvel, tratores, caminhões), e também novos métodos de produção, a partir do desenvolvimento de teorias da administração (FREEMAN; LOUÇÃ, 2002). Para Perez (2002), as indústrias que formaram a chave para o crescimento do período foram as seguintes: automotoras, petróleo e gás, motores a combustão, aparelhos elétricos e de refrigeração e alimentos congelados. Para a autora, o evento de atração tecnológica se deu com o lançamento do modelo T, pela Ford em 1908.

Uma das principais novidades da quarta onda de Kondratiev foi a elaboração de uma mentalidade produtiva, o Fordismo (FREEMAN; LOUÇÃ, 2002), que trouxe retornos de escala e de escopo, alterando inclusive as estruturas corporativas, porém o início da produção em massa trouxe também especulação em massa. $\mathrm{O}$ acesso da população americana à bolsa de valores aumentou e a quantidade de idle money capaz de alavancar investimentos cresceu, deslocando o preço dos ativos negociados na bolsa em relação ao seu valor real.

O crescimento expressivo de investimentos na bolsa de valores aumentou a quantidade de capital financeiro envolvido em transações econômicas. O boom de descobertas e o ambiente propício ao crescimento estimularam os investidores a correrem riscos na hora de buscarem retornos melhores, esses investimentos eram deslocados à nova constelação produtiva. Em outubro de 1929, o descolamento de valores do mercado financeiro atingiu seu ápice, estourando a bolha e levando milhões de americanos à bancarrota.

A parte subsequente, de re-equilíbrio entre o capital financeiro e o capital produtivo, foi longa. O período de sinergia que se desenrolou com a quebra da bolsa dos Estados Unidos até as crises do petróleo na década de 70, teve na sua fase inicial de recuperação econômica programas de estímulo à produção e também programas do governo que consolidou a indústria automobilística como o cerne do desenvolvimento e crescimento econômico do século XX. As medidas de Roosevelt, como o New Deal, favoreceram a abertura de estradas, as construções de 
http://dx.doi.org/10.5007/2175-8085.2017v20n2p71/

centrais elétricas, ampliando a infraestrutura responsável pela difusão da revolução tecnológica. A recuperação foi tamanha que a década dos anos 1950 é chamada de Golden Age nos EUA.

Os anos 70 marcam o início da exaustão do modelo. As economias mais desenvolvidas se estagnaram e ficaram dependentes das novas formas de energia, como o petróleo. Como consequência, na fase da maturidade, houve crises dessa matriz energética e além de novos investimentos em produção, boa parte do dinheiro investido foi na tentativa de se encontrar fontes alternativas, como a eólica e a solar, mostrando o esgotamento do sistema petroleiro.

Com a mudança do eixo econômico para as Américas, os Estados Unidos se tornaram o centro do desenvolvimento econômico mundial e o fim da $1^{\mathrm{a}}$ Guerra fez crescer a esperança de um mundo melhor, porém, a bolha financeira formada teve efeitos catastróficos quando estourou. Após a crise se espalhar para a Europa, com o fim da $2^{\text {a }}$ Guerra, foi organizado o sistema de Bretton Woods, cuja função seria controlar o sistema financeiro mundial. As instituições criadas perduraram e uma das suas principais atribuições foi o fim da conversibilidade do ouro-dólar. Novamente, constata-se os efeitos da bolha financeira sobre um paradigma tecno-econômico, capaz de alterar as interações, as dinâmicas econômicas e forçar alterações políticas e sociais. A mudança para o sistema de Bretton-Woods foi a forma visível dos efeitos da crise, e, ao mesmo tempo, foi a fundação para o surgimento de um novo paradigma, quando se deu a migração para o capital produtivo.

\section{O PARADIGMA DA MICROELETRÔNICA}

$\mathrm{Na}$ quinta onda longa de Kondratiev, a tecnologia responsável pela alteração paradigmática foi a microeletrônica. De acordo com Perez (2002) o evento que caracterizou o momento inicial do surto de desenvolvimento foi o lançamento do microprocessador da Intel nos Estados Unidos, em 1971. Esse evento marcou o início de uma nova capacidade tecnológica e também de uma nova forma de interação entre as empresas, as pessoas e a sociedade de modo geral. Os limites técnicos regulatórios e mercadológicos que antes separavam os diferentes segmentos da indústria são, a partir deste paradigma, rompidos pela possibilidade da incorporação de dispositivos eletrônicos em uma gama imensa de produtos e da sua integração ao mundo digital (TIGRE; RIPPER; ROSELINO, 2010). 
Um exemplo de disputa tecnológica que caracteriza o período de deployment do paradigma foi o armazenamento móvel, como, por exemplo, o disquete. A tecnologia inicial, do disquete, foi sendo constantemente modificada e melhorada, com alterações em sua forma e capacidade, depois substituída pelo CD e posteriormente pelo pen drive. Esse exemplo evidencia como o período de irrupção tecnológica, ou frenesi, causa uma pluralidade de tecnologias a serem filtradas e investidas pelo capital financeiro a fim de superarem a concorrência e se tornarem a principal forma de comércio, se estabelecendo como o padrão utilizado.

A quinta onda de Kondratiev se desenvolveu na aceleração do mercado mundial, na globalização das economias e no aflorar das tecnologias de comunicações digitais. Tais tecnologias reduziram drasticamente o custo de conservação, processamento, comunicação e disseminação da informação (PEREZ, 2002) e possibilitaram a fragmentação do processo produtivo (GROSSMAN; ROSSI-HANSBERG, 2006).

O novo paradigma tecnológico propiciou mudanças radicais no capitalismo a tal ponto que se chega a falar em sua nova fase - Fase da 'Sociedade ou Economia da Informação e do Conhecimento', 'Sociedade e Economia em Rede' ou ainda 'Economia do Aprendizado' (CASSIOLATO et al., 2010). Tal fase é marcada pela mundialização da economia, representando uma ruptura em relação à prosperidade dos 'trinta anos gloriosos', a 'Era de Ouro' do capitalismo. A economia mundial passou a experimentar uma expansão desconectada de crescimento, i.e., a expansão não está mais articulada, da mesma forma que já esteve, com a produção e os investimentos, e com aumento de emprego e elevação dos salários (FURTADO, J., 1999). A sequencia de Revoluções Tecnológicas desde a primeira Revolução Industrial até o surgimento das tecnologias de informação e comunicação (TIC) ajudou a forjar um vasto conjunto de transformações estruturais que resultaram em uma economia global de complexidade maior do que a economia que originou o primeiro big bang tecnológico (ALBUQUERQUE, 2016).

A busca incessante por novas tecnologias, a instalação de novas empresas e as novas formas de se pensar atraiu o capital especulativo para essa nova indústria. $O$ excesso de investimentos acabou por criar a bolha estrutural do paradigma, a bolha da internet (dot com) na virada do milênio. $\mathrm{O}$ excesso de investimento, assim como ocorreu nas ondas anteriores, fez com que o preço dos ativos se descolasse da realidade e, também, sobrecarregou as expectativas da economia que passou a viver em duas realidades distintas, a economia real e a virtual. Rev. Text. Econ., Florianópolis, v. 20 n. 2, p. 71 - 96, ago/dez. 2017 ISSN 2175-8085 
A formação da bolha da Internet se deu com um excesso de confiança no setor de eletrônicos e um aumento de investimentos. Assim que muitas empresas se tornaram públicas na Nasdaq - Yahoo, Amazon, TheGlobe.com, por exemplo - seus valores de mercado subiram rapidamente. Por exemplo, as ações da TheGlobe.com em novembro de 1998 atingiram 606\% de ganhos (Figura 3), como mero resultado especulativo.

Uma das principais razões para isso foi o desenvolvimento do próprio setor financeiro, que viu ao longo do século XX o avanço do venture capital e dos derivativos. Normalmente associadas às famílias e banqueiros, viu-se no século passado a capacidade de capitalização e a de capilarização crescerem, sendo assim, capazes de aumentar e disseminar a quantidade de empresas investidas. Essa nova forma de investimento está intimamente relacionada à descentralização econômica causada pelos impactos do avanço da indústria de comunicações, uma vez que a internet, eixo central da nova configuração econômica, também causou uma descentralização. Compõem essa nova rede, o sistema global de telecomunicações (cabos de fibra ótica, rádio e satélites), a internet, todos os serviços associados, como e-mail, os transportes de alta velocidade interligados e também as novas e flexíveis funções da rede elétrica (PEREZ, 2002).

Após o estouro da bolha financeira, houve a instalação e a propagação das novas indústrias do paradigma. A instalação se deu com as indústrias da informação, a produção de computadores, a microeletrônica, o software, as telecomunicações, os novos materiais e os instrumentos de controle (PEREZ, 2002). Essa nova configuração formou uma rede de infraestrutura que ficará de legado, assim como as ferrovias, as rodovias, a mecanização e a eletricidade ficaram. 
Figura 3 - Bolha da Internet, Nasdaq Composite Index.

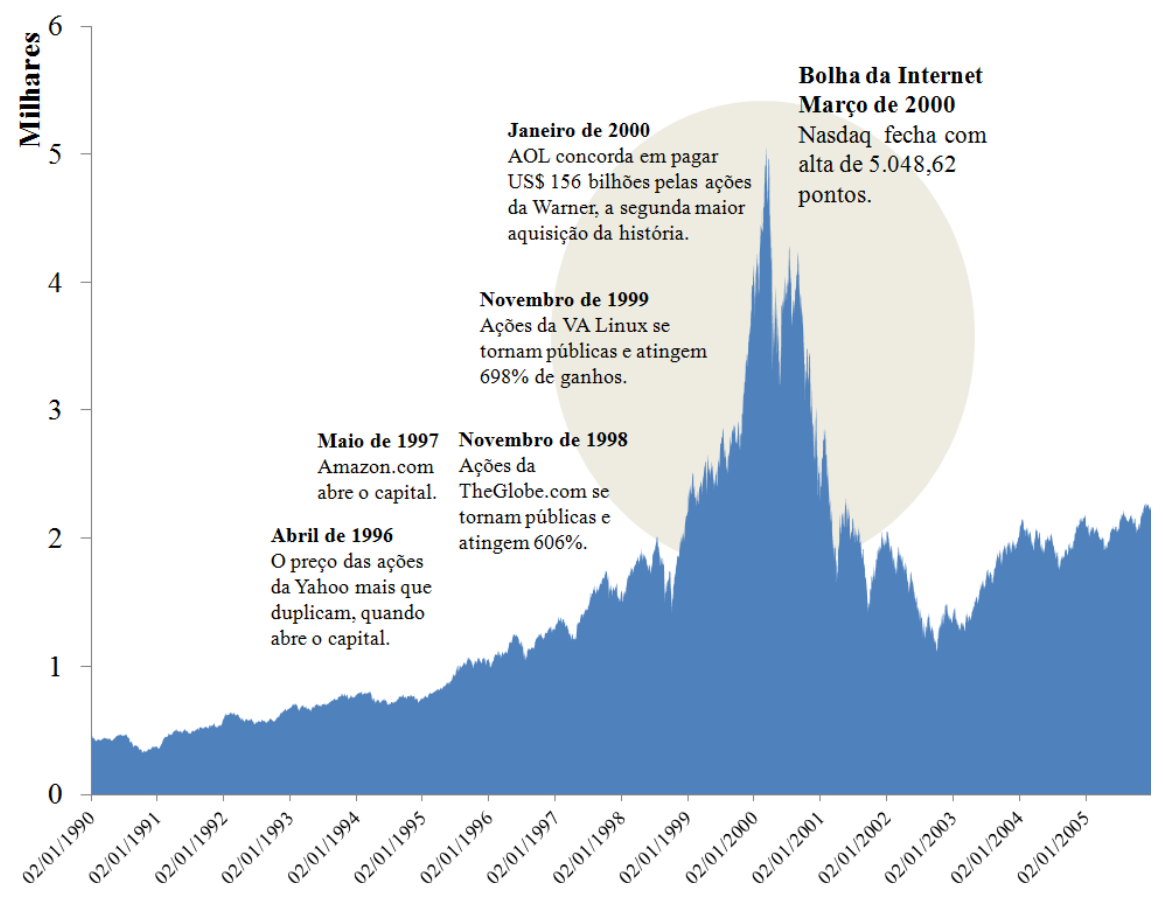

Fonte: Elaboração própria a partir do Nasdaq Composite Index, daily close.

A nova gama de possibilidades gerou uma onda de incerteza, apontada por Freeman e Louçã (2002, p. 301): “Great uncertainty still attends more profound social and political changes associated with ICT including the diminished capabilities of national governments to tax and regulate powerful multinational firms and the rise of a new culture of 'virtual reality. Em outras palavras, após a crise financeira, os governos e órgãos institucionais voltam-se para a regulação do mercado financeiro. Cria-se uma nova ordem, com novas funções para os órgãos internacionais, tentando direcionar a economia para o viés produtivo. (PEREZ, 2002).

Outra característica desse período é que ele está associado à parte de upswing da onda de Kondratiev (1925), ou seja, é o período de expansão das economias capitalistas. Após a crise, a estrutura econômica converge para as economias que se mostram resilientes à crise financeira e, também, para as que sobreviveram à intensa canibalização inicial e passaram a se tornar dominantes. A partir daí os ativos do mercado financeiro voltam ao patamar real e os investimentos se tornam em capital produtivo, a especulação é reduzida e as plantas físicas passam a ser a forma dominante de investimento. 
O estouro da bolha financeira causou impactos na sociedade que passou a pressionar por mudanças institucionais a fim de evitar novos problemas relacionados à especulação financeira. Ademais, para evitar crises trágicas surgiram o Big Bank e o Big Government ${ }^{2}$ (BRAGA, 2009).

No ano de 2004 houve a reunião para a formação do $2^{\circ}$ acordo de Basileia, onde foram decididas novas diretrizes para o mercado financeiro. Assim como a crise de 2008 exigiu uma nova reunião, formando o Basileia III, mostrando a constante evolução tanto do mercado financeiro quanto das pressões sociais por mudanças, reforçando o caráter cíclico das mudanças paradigmáticas e também da interação entre as esferas do surto de desenvolvimento. Um exemplo concreto dessas reivindicações pode ser analisado no movimento Occupy, onde manifestantes foram às ruas protestar contra o capital financeiro, o excesso de poder dos bancos e de organizações correlatas, além de criticarem a intensa concentração de renda no período.

Porém, há estudiosos que dizem que o período atual já seria pertencente à sexta onda longa de Kondratiev (Figura 4). O relatório da Allianz Gobal Investors (2010) sugere que a recente crise financeira (de 2008) pode marcar o período de recuperação no vale da onda de Kondratiev e ainda quatro fatores são apontados no relatório que justificam essa posição: i) 0 potencial para futura exploração de uma inovação básica antiga está em exaurimento (ciclo de 40-60 anos); ii) o excesso de capital financeiro (versus capital físico); iii) o período de severa recessão (período de mudança radical); e iv) as transformações sociais e institucionais.

Além disso, o referido relatório levanta a suspeita de que vemos a migração dos investimentos para o setor de ciências da saúde, com o fomento ao desenvolvimento da biotecnologia e energias renováveis, áreas com potencial de mudar o sistema de consumo e de saúde da população, reconfigurando toda a economia. É visto, também, o surgimento de incubadoras de empresas desse nicho, justamente com a finalidade de auxiliar a pesquisa e desenvolvimento de pequenos empreendedores. Pode-se citar que a internet ainda deixou um legado importante nesse aspecto, a existência do crowdfunding, onde cada pessoa pode buscar o financiamento de sua ideia de forma descentralizada, com a diminuição dos riscos e a expansão do número de colaboradores.

2 O Big Bank - Banco Central - "tem o papel intrínseco de resgatar o capitalismo financeiro nas encruzilhadas em que esse dá sinais de que não é capaz de resolver as instabilidades globais que ele mesmo criou" (BRAGA, 2009, p. 93). O mesmo pode ser dito do Big Government que passou a injetar liquidez para que empresas gigantes consideradas "too big to fail" pudessem evitar de entrar em colapso. Ambos os termos são usados de forma pejorativa.

Rev. Text. Econ., Florianópolis, v. 20 n. 2, p. 71 - 96, ago/dez. 2017 ISSN 2175-8085 
Figura 4 - Ciclos longos de Kondratiev, 10-year yield on the $S \& P 500$.

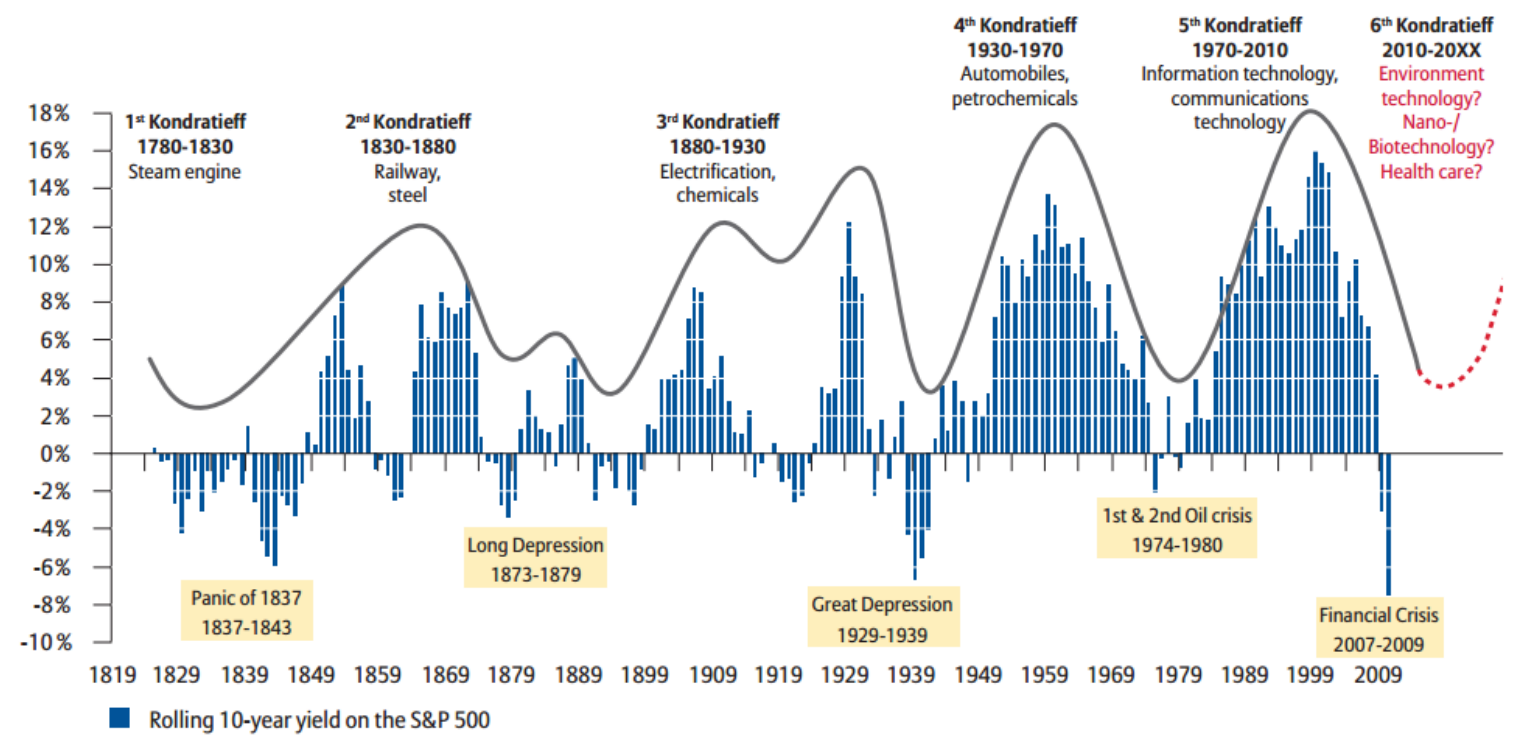

Fonte: Allianz Global Investors (2010, p. 06).

A sociedade está em um momento de transformação, há percepções de características de um período de sinergia, exemplificado pelo crescimento de serviços baseados na infraestrutura nova da quinta onda, empresas start-up, sistemas de financiamento coletivos, investidores anjos e também serviços de comunicação avançados como celulares e o desenvolvimento das redes de fibra ótica. Há também demonstrações de uma possível gestação de um novo paradigma, o das ciências da vida, com a migração do idle money para essas áreas. Recordando o esquema de Perez (2002) de que o período de fim de uma onda longa se sobrepõe ao início da outra, difícultando a percepção do momento atual.

Desse modo, avanços em nanotecnologia, biotecnologia e novos materiais (Industria 4.0) (SCHWAB, 2016) podem propiciar uma constelação de tecnologias que poderão gerar um novo paradigma tecno-econômico. Por exemplo, os novos avanços tecnológicos em processadores mais eficientes, software para análises de big data e redes neurais computacionais mais sofisticadas já têm permitindo o surgimento de tecnologias baseadas em inteligências artificial (machine learning e deep learning) que têm a potencialidade de se tornarem uma tecnologia de uso geral (KELNAR, 2016; HUBER, 2017; MAKRIDAKIS, 2017). No entanto, somente o desenrolar dos fatos evidenciará se ainda vigora o período de deployment da quinta onda ou se já está em gestação o próximo, adentrando a sexta onda de crescimento econômico. 
http://dx.doi.org/10.5007/2175-8085.2017v20n2p71/

\section{CONSIDERAÇÕES FINAIS}

Uma Revolução Tecnológica combina produtos, processos e indústrias novas com outras pré-existentes (AREND, 2012). Durante seu período de instalação, há uma expansão acelerada do crescimento vinculado à nova tecnologia, gerando lucros extraordinários. Desse modo, há inflação no valor dos ativos. Trata-se do momento de especulação acerca do novo, de descolamento do valor real, das novidades que podem surgir com a inovação nascente. O período de instalação é dominado pelo capital financeiro em sua estrutura. Com o desdobramento da Revolução Tecnológica, o crescimento econômico está coerente com os investimentos e com os valores reais, não há o descolamento nem a especulação, características do período anterior. Ocorrem as chamadas 'eras de ouro', isto é, acontecem a maior expansão produtiva e o aumento de renda real. Há a saturação do mercado, a consolidação das indústrias, há poucos produtos novos sendo lançados, chega-se ao grau máximo de difusão tecnológica. Ao contrário do período de instalação, o de desdobramento tem como motor o capital produtivo, daí a sua característica de maior coerência entre produção e crescimento, no valor dos ativos. (PEREZ, 2009).

A atual Revolução Tecnológica - Era da Microeletrônica - é marcada por mudanças engendradas na nova fase do capitalismo, com a ascensão do liberalismo, a imposição financeira sobre a produtiva e comercial, reafirmando o primado da dominância financeira (FURTADO, J., 1999). As atuais forças econômicas e tecnológicas influenciam a defasagem entre invenção e inovação e a velocidade do processo de difusão de forma distinta das Revoluções Tecnológicas anteriores. Desse modo, há uma mudança de timing em relação às antigas Revoluções Tecnológicas e a justaposição de big bangs em diferentes países e setores (ALBUQUERQUE, 2016).

Essas mudanças estruturais alteraram a noção de que a inovação tecnológica dá início a ciclos com duração de quatro a seis décadas. De acordo com a proposta baseada em Kondratiev, o período do ciclo da atual Revolução Tecnológica (baseada nas TICs) já deveria estar em declínio, Perez (2010), sinaliza que já estaríamos no início da sexta onda de Kondratiev, sendo as tecnologias da próxima Revolução Tecnológica baseadas na biotecnologia, nanotecnologia, bioeletrônica e novos materiais. Contudo, diferentemente dos ciclos anteriores, sem a transição da hegemonia do capital financeiro para o capital produtivo. Ou seja, estaríamos iniciando a sexta 
http://dx.doi.org/10.5007/2175-8085.2017v20n2p71/

onda de Kondratiev sem que o capital produtivo tomasse as rédeas do desenvolvimento, o que questiona a aplicabilidade da sistematização realizada por Perez (2010).

\section{REFERÊNCIAS BIBLIOGRÁFICAS}

ALBUQUERQUE, E.. Dinâmica das Revoluções Tecnológicas: Mudança técnica, dinâmica industrial e transformações do capitalismo. XVII Seminário sobre a Economia Mineira, Diamantina (MG), 2016.

ALLIANZ GOBAL INVESTORS. The sixth Kondratieff: long waves of prosperity. 2010. Acesso em: 30 de outubro de 2016, Disponível em: $<$ https://www.allianz.com/v_1339501901000/media/press\%20/document/other/kondratieff_en.pd $\underline{\mathrm{f}}>$.

ADELMANN, B.. The panic of 1893: boosting bankers' money and power. New American, v. 27, n. 8, p. $35,2011$.

AREND, M.. Revoluções tecnológicas, finanças internacionais e estratégias de desenvolvimento: um approach neo-schumpeteriano. Ensaios FEE, v. 33, n. 2, p. 363-396, 2012.

BRAGA, J. C. S.. Crise sistêmica da financeirização e a incerteza das mudanças, Revista Estudos Avançados, 23 (65), 2009.

BOUGHEY, J.; HADFIELD, C.. British canals: the standard history. Stroud, Gloucestershire, Inglaterra: The History Press. ed.9. 2008.

CAMPBELL, G.; TURNER, J. D.. Dispelling the myth of the naïve investor during the british railway mania, 1845-1846. Business History Review, vol.8. 2012.

CASSiOlAtO, J. E.; GADELHA, C. A. G.; AlBUQUERQUE, E. M.; TIGRE, P. B.; CAVAlCANTI, P. F. M. B.. Introdução. In: CASSIOLATO, J. E. (Orgs.). Perspectivas do investimento na economia do conhecimento. Rio de Janeiro: Synergia, 2010. cap. 1, p.1-6.

CHEW, R. S.. Certain Victims of an International Contagion: The Panic of 1797 and the Hard Times of the Late 1790s in Baltimore". Journal of the Early Republic. v. 25, n 4, 2005.

COUTINHO, L.; BELLUZZO, L. G.. Financeirização da riqueza, inflação de ativos e decisões de gasto em economias abertas, Economia e Sociedade, v. 7, n. 2 (11), pp. 137-150, 1998.

FREEMAN, C.. The Kondratiev long waves, technical change and unemployment. In: OECD. Structural determinants of employment and unemployment. vol. 2, Paris: OECD, pp. 181-196, 1977

FREEMAN, C.; LOUÇÃ, F.. As time goes by: from the industrial revolutions and to the information revolution. Oxford: Oxford University, 2001. 
http://dx.doi.org/10.5007/2175-8085.2017v20n2p71/

FREEMAN, C.; PEREZ, C.. Structural crisis of adjustment: business cycles and investment behaviour. In: DOSI, G.; FREEMAN, C.; NELSON, R.; SILVERBERG, G.; SOETE, L. (eds). Technical change and economic theory. London: Pinter, 1988, p. 38-66, 1988.

FURTADO, J. Mundialização, reestruturação e competitividade: a emergência de um novo regime econômico e as barreiras às economia periféricas. Novos Estudos CEBRAP, v. 53, p. 97 $118,1999$.

GRININ, L.; GRININ, A.; KOROTAYEV, A.. Forthcoming Kondratieff wave, Cybernetic Revolution, and global ageing. Technological Forecasting \& Social Change, v. 115, p. 52-68, 2017.

GROSSMAN, G. M.; ROSSI-HANSBERG, E. The Rise of Offshoring: It's Not Wine for Cloth Anymore. Economic Policy Symposium on The New Economic Geography: Effects and Policy Implications. Jackson Hole, Wyoming 2006.

HUBER, T. A. (2017). Is Artificial Intelligence really the next technological revolution? A comparison of AI with previous technological breakthroughs. Medium. Acesso em: 28 de novembro de 2017, disponível em: <https://shift.newco.co/is-artificial-intelligence-really-thenext-technological-revolution-6fefe 31b9765>

KELNAR, D.. (2016). The fourth industrial revolution: a primer on Artificial Intelligence (AI). Medium. Acesso em: 28 de novembro de 2017, disponível em: <https://medium.com/mmcwrites/the-fourth-industrial-revolution-a-primer-on-artificial-intelligence-ai-ff5e $7 \mathrm{fffcae} 1>$.

KONDRATIEV, N. D. (1926b) Long cycles of economic conjuncture. In: The works of Nikolai D. Kondratiev. Edited by N. Makasheva, Samuels, W.; Barnett. London: Pickering and Chato (1998), pp. 25-60.

v.17, 1935.

.. The long waves in economic life. Review of Economic Statistics, Cambridge, EUA, .. The major economic cycles. Moscou: Voprosy Koniunktury. 1925.

LASTRES, H. M. M.; FERRAZ, J. C. Economia da Informação, do Conhecimento e do Aprendizado. In: LASTRES, H. M. M. e ALBAGLI, S. (Orgs.). Informação e globalização na era do conhecimento. Rio de Janeiro: Campus, 1999. p.27-57.

LLOYD-JONES, R.. The first Kondratieff: the long wave and the British industrial revolution. The Journal of Interdisciplinary History. Cambridge, EUA, v.20, n.4, p.581-605, 1990.

MAKRIDAKIS, S.. The forthcoming Artificial Intelligence (AI) revolution: Its impact on society and firms. Futures, 90, 46-60, 2017.

MARX, K.. O Capital. São Paulo: Abril Cultural, Volume III, Livro II, 1985.

Rev. Text. Econ., Florianópolis, v. 20 n. 2, p. 71 - 96, ago/dez. 2017 ISSN 2175-8085 
http://dx.doi.org/10.5007/2175-8085.2017v20n2p71/

MCKEEVER, D.; RAPORT, M.. Technology and the revolutions of 1848 and 2011. Disponível em <http://www.kas.de/wf/doc/kas_34903-1522-230.pdf?1307091 92554> acessado em $15 / 6 / 2016$.

PEREZ, C. Technological revolutions and financial capital: the dynamics of bubbles and golden ages. Cheltenham: Edward Elgar. 2002.

- Dinamismo tecnológico e inclusión em América Latina: uma estratégia de desarrolloproductivobasada em lós recursos naturales. Revista da Cepal,, 100 - abril, 2010

ROSENBERG, N.; FRISCHTAK, C. R.. Inovação tecnológica e ciclos de Kondratiev. Pesquisa e Planejamento Econômico, v. 13, n. 3, p. 675-706, 1983.

SCHUMPETER, J.. Business cycles: a theoretical, historical and statistical analysis of the capitalist process. Philadelphia: Porcupine, 1989 [1939].

. Capitalism, socialism, and democracy. 6 ed. New York: Routledge. 1943

. The theory of economic development. New York: Oxford University Press. 1912.

SCHWAB, K.. (2016). The Fourth Industrial Revolution: what it means, how to respond. Global Agenda - World Economic Forum. Acesso em: 28 de novembro de 2017, disponível em: $<$ http://www.weforum.org/agenda/2016/01/the-fourth-industrial-revolution-what-it-means-andhow-to-respond/>.

TIGRE, P. B.; RIPPER, M. D.; ROSELINO, J. E. S. Tecnologias da Informação e Comunicação (TIC). In: CASSIOLATO, J. E. (Orgs.). Perspectivas do investimento na economia do conhecimento. Rio de Janeiro: Synergia, 2010. cap. 4, p.85-144. 